\title{
IT Education's Failure to Deliver Successful Information Systems: Now is the Time to Address the IT-User Gap
}

\author{
Joan Mann \\ Old Dominion University, Norfolk, Virginia, USA \\ imann@odu.edu
}

Executive Summary

IT curricula were created in business schools because traditional computer scientists had problems building information systems that were acceptable to the people that use them. Now, many years later, the percentage of unsuccessful information systems is still alarmingly high. Research in this area tended to be focused on the project level and seemed to ignore the growing conflict between end-users and the IT department as a whole.

The IT-User gap is pervasive and takes many different forms. In fact, the IT-User gap has become such a problem that many organizations are taking matters into their own hands by creating new hybrid positions to bridge the gap. Personnel in these positions bridge the gap by helping end-users deal with the IT personnel and vice versa. Moreover, despite extensive obstacles, these people are taking on the challenge and becoming quite successful. The names of these positions may vary widely (relationship manager, IT-User Liaison, etc.) but they all have similar roles in the organization.

This paper begins with the premise that the IT-User gap will not disappear but that we could be doing more in our IT curricula to address the gap. First, the curriculum for IT majors should recognize that the role of IT professionals is changing in organizations and that the trend is for IT professionals to need stronger interpersonal skills and an organizational learning perspective. Second, the curriculum must be modified to give more than just lip service to the importance of these skills.

Changes to the IT curriculum, however, may not be enough. If organizations have found hybrid personnel to be indispensible, then it is time that IT curricula begin to prepare students to take on this new career. IT programs often have students that are not very strong programmers but yet really like working with computers. Rather than encouraging the students to change majors, we should recognize that organizations can benefit from their skills too. This paper addresses the issue by presenting two enhancements to the traditional IT curriculum. The first is a hybrid major that emphasises that the person would need both technical and inter-personal skills. The second is a hybrid minor that would allow non-IT business majors or even non-business majors to enhance their technical skills enough to be effective liai-

Material published as part of this journal, either on-line or in print, is copyrighted by the publisher of the Journal of Information Technology Education. Permission to make digital or paper copy of part or all of these works for personal or classroom use is granted without fee provided that the copies are not made or distributed for profit or commercial advantage AND that copies 1) bear this notice in full and 2) give the full citation on the first page. It is permissible to abstract these works so long as credit is given. To copy in all other cases or to republish or to post on a server or to redistribute to lists requires specific permission and payment of a fee. Contact Editor@JITE.org to request redistribution permission. sons between their work group and the IT department.

Keywords: IT-User Gap, IT Curriculum, Hybrid Workers, IT-User Liaisons, Relationship Managers 


\section{Introduction}

Information technology has become increasingly important to organizational health and even survival over the years; yet the success rate for information technology (IT) development projects is still frightfully low and runaway projects are all too common. According to a study of over 8,000 projects by the Standish Group (Standish Group, 1995):

- $16.2 \%$ were successful (on time, on budget, full functionality)

- $52.7 \%$ were challenged (over budget, time and fewer features)

- $31.1 \%$ were impaired (project was canceled)

Moreover, these rates are not significantly different than when systems were built in the 70's and 80's (see Mann, 1996 for a review of failure literature).

\section{IT Education and Unsuccessful Information Systems}

Information technology departments were created in business schools because system failures were attributed to problems with the interaction between traditional computer scientists and stakeholders of the system to be built. Computer scientists were very capable at building systems but had difficulties creating systems that met end-users' needs. This was the beginning of the IT/User gap -- a phrase that encapsulates all dysfunctional aspects of the relationship between end-users and the personnel in the IT department. In these early days, the IT/User gap was thought to stem from the lack of business knowledge on the part of computer scientists.

Information technology curricula were, therefore, designed to address this issue by giving students both exposure to various business disciplines and a strong grounding in technical skills and techniques. Moreover, courses such as Systems Analysis and Systems Design emphasized the importance of accurately capturing user requirements and building systems that are aligned with those requirements. The systems developed in programming classes solved real life business problems and in telecommunications courses emphasized how networks support business operations.

Later, business schools also realized that the IT/User gap might also stem from users not having enough knowledge about IT. At that time, courses on IT fundamentals were introduced into core business curricula at both the undergraduate and graduate level.

So, the IT-User gap has been attacked from the IT side as well as the User side, but still development projects fail to achieve a successful outcome. What should be done next? A possible answer may be found by examining the nature of the IT-Gap, current organizational practice and then reflecting on ways IT pedagogy could be reworked to address the many facets of this chasm between the IT department and end-users.

\section{Research on the IT-User Gap}

The dynamics between IT and end users in development projects has been a subject of numerous research papers throughout the 70's and 80's, including papers on user involvement, user acceptance/diffusion and user satisfaction. A poor IT-User relationship has often been cited as a cause of failure in development projects but few studies have examined the dynamics of this relationship. One exception is Seligman (2000) who proposes an adopter-centered process model of IT adoption based on Karl Weick's concept of sensemaking. 
There is much less literature on the gap between end users in general and the IT department as a whole. Some researchers have shown that IT personnel have different personality traits than the general population, which might partially explain why there is a gap (ex: Wynekoop \& Walz,1998). Other researchers have focused on identifying important skills necessary in the IT shop (Martinsons \& Chong, 1998), including those necessary for working with end users (Shore, 1998). Many researchers have examined what makes and information center successful as a service arm of the IT department (Dhillon, \& Lee, 2000) but these studies focus more on the tasks performed (Guimaraes, Gupta \& Rainer, 1999; Essex, Magal \& Masteller, 1998) than whether there is an effective IT-User relationship.

Recently, some authors have proposed frameworks that focus on the IT-User gap. Kettinger (1995) presents a model where gaps can occur between IT services delivered and the user's perception of the service expected. The suggested solution is to use the SERVQUAL measures of service from the marketing area. Unfortunately, this instrument does not directly address the IT-User relationship. Leonard (2001) attempted to link the effectiveness IT-User relationship to the ability of obtaining strategic IT alignment through use of a process model. The model focuses on the IT-User relationship as the process by which alignment is achieved.

Current practitioner literature on the other hand, is increasingly reporting that a serious gap exists and that organizations are using a diversity of approaches to deal with it. The next section reports on this literature, with references to academic research when relevant.

\section{IT-User Gap Characteristics}

According to research and practitioner literature the IT-User gap can take on many different forms. In fact, there are actually several different types of gaps (see Figure1 and the subsequent text for definitions of each one):

- Perspective Gap -- incomplete viewpoints

- Ownership Gap -- who owns/is responsible for infrastructure/processes

- Cultural Gap -- professional acculturation

- Foresight Gap -- who sees the future better?

- Communication Gap -- inability to understand what the other is saying

- Expectation Gap -- who is realistic?

- Credibility Gap -- issues of past history

- Appreciation Gap -- lack of recognition

- Relationship Gap -- stereotypes never checked

Figure 1: Types of IT-User Gaps

- Perspective Gap: when the viewpoint of one group is incomplete. IT sometimes forgets that systems must provide value to the business by meeting evolving business goals and that the world does not revolve around the IT department (Scalet, 2000/2001). End-users sometimes forget that IT is only a tool not a cure-all and become dazzled by it (Pender, 2000/2001).

- Ownership Gap: Too often IT feels ownership over the infrastructure and end-users feel ownership over the business processes. This leads to territorial conflicts that strain the IT/User relationship and create mis-conceptions (Lin \& Conford, 2000; Avital \& Vandenbosch, 2000). End-users feel IT personnel are technical elitists and IT staff feels end-users are reactionary. 
- Cultural Gap: when the different groups have different traits, values, working behaviors, and/or priorities because each group either attracts certain kinds of individuals or it acculturates members in the group. For example, IT people tend to be more introverted, analytical and tend to use rational persuasion to influence others. Business end-users tend to be more extroverted, intuitive and use more sophisticated influence strategies (Shah, et al., 1994; Champy, 1997). Both end-users and IT personnel adopt the culture of their respective professions. These differences in behaviors and norms can make it difficult for effective interaction to occur.

- Foresight Gap: when one group is better able to see the future but cannot convince the other group. IT may be in a better position to foresee that user solution will not work from a technical standpoint. On the other hand, end-users may be better able to determine why the project or the system to be built will not be accepted or will have a negative impact on the current situation (Fisher, 1999).

- Communication Gap: when one group fails to understand what the other means. Users feel that IT speaks in jargon but users have their own jargon as well. IT fails to translate business users needs into useful systems because they don't fully understand business processes(New Group Will Bridge, 1999; Shah, et al., 1994; McCann, 1995).

- Expectation Gap: when end-users have unrealistic expectations of what IT can do. Ironically, users expect more from IT because they have become more computer literate or because IT has done such a good job ('IT will always come through') (Whiting, 1998; Melymuka, 1998). On the other hand, IT is notorious for promising more than they deliver and expecting all users to be technologically naive. The client/server environment has also been blamed for the expectation gap because it makes the information infrastructure of the organization look more adaptable than it is.

- Credibility Gap: when the track record on the IT side is poor. It may be related to systems development projects that failed but it can also be related to poor customer service, as in a help desk that doesn't help (New Group Will Bridge, 1999). IT personnel may have found end-users to be resistant to change or overly demanding in the past.

- Appreciation Gap: when one group feels the other group does not recognize their value. IT may feel their hard work, long hours and contributions to the organization go unnoticed except when something goes wrong (ex: the network is down) (Mottl, 1999; Ouellette, 1999; Wallace, 1998). There is also some evidence that IT personnel want to be more involved in business decisions but are not asked to do so (Hayes, 1998). IT personnel don't always appreciate that end-users are experts in their knowledge domain and the social complexities of their situation.

- Relationship Gap: when the two groups do not interact frequently and effectively enough. Each group's pre-judgements of the other group never become resolved. Relationship becomes 'us' versus 'them' (Shah, et al., 1994; Scalet, 2000/2001).

The many different forms of IT-User Gap may well contribute to failed systems development projects and the strained relationship between IT and users. Moreover, the longevity of the problem has prompted organizations to take steps to solve it on their own.

\section{Organizational Responses to the Crisis}

The IT/User gap problem is so pervasive that two British Computer Society members have formed a special interest group on this issue (How to Bridge, 1999; New Group Will Bridge, 1999) The group is called the Business-IT interface and it has two goals: "improve the success rate of IT projects and the acceptance of systems by end-users." In their view, organizations need more people in 'hybrid' roles. People who can "bridge the gap between business problems and IT". According to them, many organi- 
zations have people who have taken on this role. The group intends to profile these people, champion their development and improve their status. Evidence of the trend towards hiring hybrid professionals are also seen in (The New Breed, 1998; Hale, et al., 1999; Whiting, 1998) and others.

"For an increasing number of CIOs, the critical new IT jobs are less about bleeding edge technologies... the personnel concerns are more about the need to bridge the gap between traditional ways of doing business and the complex new universe in which technology is embedded in virtually every aspect of daily commerce (LaPlante, 1997)."

Recent research and practitioner authors have also pointed out the existence of these hybrid personnel and their role as intermediaries between IT and business. The need for personnel with IT and business orientations was first suggested by Meikeljohn in 1989. Since then many firms have created hybrid positions. According to a 1997 Gartner Group survey, 50\% of all firms are addressing this need to reduce the gap through relationship management (Meta Group found that $70 \%$ had some type of business technologist on staff (Whiting, 1998). Whereas the titles may vary from client service manager, customer advocate, account relationship manager, IT/Finance manager, Whiting (1998) uses the label 'relationship manager'. Relationship management, unfortunately, has a negative connotation because it implies that users or IT people need 'managing'. IT-User liaison or hybrid managers are phrases that are more accurate and less pejorative. IT-User hybrids address many aspects of the gap in three different ways: Influencing end-user behaviors/perceptions, influencing IT personnel behaviors/perceptions and acting as a

\section{Influencing End-Users}

- building relationships with business units by spending time there or being colocated there and actively interacting with business unit personnel

- educating and consulting on information technology management and strategic use

- clearly explaining the value of new technology to business managers

- creating reusable solutions and disseminating best practices across to other units

\section{Influencing IT Personnel}

- ensuring that IT is aligned with business and assisting in process reengineering

- building the credibility of IT with end-users

- improving the business orientation of the IT function by making them aware of business opportunities that might be solved with information technology

- improving the skill sets of the IT function by influencing recruiting, orientation and demonstrating effective end-user interactions

\section{Acting as a Mediator}

- making both sides aware of each other's capabilities and the complexities of each other's respective activities

- translating user needs into products/services that the IT department can provide

- acting as user liaison beyond the IT analysis and design stages of projects

- getting user support for IT initiatives and helping them get support from IT

- evaluating completed projects

- reducing conflicts between IT and users

- coordinating projects over multiple organizational and business entities

Figure 2: Potential Hybrid Activities mediator between the two groups. See Figure 2 for a list of hybrid activities under each category.

Unfortunately, these positions are often difficult for the people who have them. There can be conflicts of interest when the position reports to IT but needs to defend users over IT sometimes; or reports to a business unit but needs to defend IT. In some cases, the position is either poorly defined or lacks the authority it needs to be successful. It is difficult to build credibility without support from the IT side. Still, persons in these intermediary positions seem to manage very well by using higher level influencing skills such as negotiation, conflict management, facilitation and translation. Moreover, for the most part, they find the work highly rewarding. 
Another form of intermediary, called the business analyst comes from the business side. These are people who know what it takes to run a business and can bring together specialists from both technical and non-technical areas of the firm and work with data from a variety of sources including corporate databases. Business analyst positions are developed because "business problems do not come neatly packaged as marketing problems, accounting problems...(Miller, 1998)" and because creating information and knowledge has become a critical skill for organizations (Davenport, 1999).

Some firms, like Sears, Toys-R-Us, Alaska Airlines, and Liz Claiborne have attempted to fix the business side of the gap by taking users and placing them in the IT department (Hayes, 1997) whenever they are members of an IT project team or assigning them the IT department in order to learn to do IT work (only somewhat successful).

"Efficient? Not by half. Users bring conflict and rough, unpleasant reality into what your typical orderly IT type wishes were a delicate, finely tuned development process."

On the IT side, some firms are using technical writers as intermediaries because they are already doing translations of technical material for end-users and they are experienced at creating interfaces that are usable. Others, such as Hilton Hotels and Perdue are forcing all new IT hires to work down in the trenches.

In top-level hybrid positions, the primary goal is to take an organizational view rather than that of IT or just one business unit and to manage cross-functional teams. Persons in these positions take on a highly strategic role for the corporation and do more than address the IT/User department gap, they address the gap between IT available and how the organization uses IT. Help wanted ads often require strong business background and varied work on technology projects (LaPlante, 1997).

In any case, the IT/User gap is enough of a long-term problem that firms are increasingly developing hybrid positions and other techniques to deal with it. So what does this mean for IT curricula in the $21^{\text {st }}$ century?

\section{Implications for IT Curricula - IT Majors}

The fact that the IT/User gap still exists and is problematic for organizations means that there is something missing from our training of professionals. The solution is to either ignore the gap and let organizations create hybrid positions or to address the IT side of the gap.

A survey of executives (Rose, 1995) found that many firms are attempting to 'retool' their IT departments in three different ways:

- Retooling with respect to gaining new technical skills (e.g. mainframe to client/server)

- Retooling with respect to moving from hierarchical-based organizations to organizations where the basic unit is the team

- Retooling with respect to shifting from the traditional IT focus on technical issues to a focus on business partnerships, through the development of partnerships, and through the development of high-level functional skills by IT staff.

The survey also found that retooling was more about enhancing the IT toolbox with non-technical skills: business knowledge, consulting expertise, team-building, marketing ability and communication skills. This finding was reiterated by a research project by Meta Group, Inc. in 1996, which found that Senior IT executives feel that at least half of their personnel do not have the skills required of today's professionals, including: 
- business knowledge and familiarity with business processes

- $\quad$ solid interpersonal skills (negotiation, coaching, communication, leadership)

- customer/service driven attitude

- facility for risk taking and ability to operate under pressure

- ability to work well in cross-functional, team-based environments

- adaptability, flexibility

- $\quad$ skill in project management

- comfort at locating in business units and/or building long-term relationships with user managers (Foote, 1996)

Other authors (McGinnes, 1994; Trauth, Farwell \& Lee, 1993) have emphasized the need for a 'new IT professional' who has strong skills in communication and collaboration in a technical environment that stresses integration (to support downsizing, mergers/acquisitions and globalization) over new development. The alarming frequency of system failures are blamed on factors representative of one or more facets of the IT-User gap: 1) "weak or nonexistent project management, leading to an inability to monitor and control collaborating individuals and organizations"; 2) "failures of communication between participants, leading to ill-specified systems and poorly coordinated development efforts"; 3) "failure of analysts and users to communicate effectively, resulting in specifications that were unrealistic or failed to meet real needs."

Some have even suggested that the very role of the IT professional in the organization is changing. In addition to the traditional role of technician, IT personnel need to be vision builders, team players, alliance builders, tacticians, deliverers (O'Connor \& Smallman, 1995), relationship builders (Feeny, Willcocks, 1998), facilitators and catalysts (McGinnes, 1994).

In fact, it may be helpful to use the analogy of a physician or psychoanalyst:

"Both types of analyst [psychoanalysts and systems analysts] are highly trained in their respective fields, with extensive bodies of highly technical knowledge to master; they must be good listeners; they must appreciate the difference between what people say and what they mean; they must be able to adapt their own manner to suit the situation, and they must be able to deal with people of different types and from different backgrounds. After the consultation, both sorts of analysts must be able to provide an objective and analytical account of what has gone on, drawing unbiased conclusions. Despite these parallels, the training methods practiced in the two disciplines are remarkably different (McGinnes, 1994)."

IT personnel need to function very much like a physician as well and the need for IT majors to develop an effective 'bedside manner' is critical . Physicians have to make clinical decisions in ambiguous circumstances (when to remove a respirator?, who to treat first in an emergency?, who gets the organ transplant?). IT majors should be trained for similar decisions (when to kill a project, prioritizing projects by business value not ease of development, putting IT resources where they help the organization most). On the negative side, physicians often make the same mistakes as IT professionals. Not everyone that comes to a physician's office wants medicine or surgery and not every user needs a website (culture gap). Sometimes a doctor has to say "no" to a patient that is insisting on medicine or surgery and sometimes a doctor has to be brutally honest about the ramifications of taking a specific medicine or undergoing surgery (foresight gap). In the same way, IT professionals sometimes need to challenge business units to really evaluate the business value of a system and for them to confront the full ramifications of implementing a given technology. 
The new roles of IT personnel mentioned in this section and the previous section are difficult to build without prior training. But, even as recently as the 1995, Guideline for Undergraduate IT Curriculum, the course descriptions of required courses hardly mentioned social skill training, despite the fact that Interpersonal Relationships, Management and Professionalism were included as representative abilities/knowledge required for IT program graduates (Couger, et al., 1995). Even when the curriculum is revised as to its goals, the tactics have not addressed its fundamental flaw.

"It can be argued that existing courses in information systems and computer science are productoriented rather than process-oriented. They focus on end results -- the information systems -rather than the processes used to arrive at them (Mcginnes, 1994).

Further evidence that academics are unaware of this shift in the needs of the IT workplace can be found in (Trauth, Farwell \& Lee, 1993). In multiple surveys of academics and practitioners, they found each group had different expectations of what was important for IT graduates to learn. Academics stressed traditional systems development and $3^{\text {rd }}$ generation programming, whereas practitioners focused more on rapid application development and integration, $4^{\text {th }}$ generation languages and aligning new technology to business needs. When asked which skills were most important for the future, practitioners rated productive user/client relationships first whereas academics ranked it in $8^{\text {th }}$ place.

One issue related to communication/collaboration that may need to be addressed is the gap between the way technical majors are acculturated versus the way they need to behave when dealing with end users. Acculturation is the process by which a human being learns the cultural traits of its societal group. It is not unusual to see two technical people meeting for the first time participating in a swift competition over jargon to see who is more technically competent (for a description of this dynamic in university Computer Science programs, see the work-in-progress (Margolis and Miller, n.d.). They label this pecking order: the "I know more about computers than you do" hierarchy).

This behavior sends several messages:

- Your status comes from being able to 'out-jargon' those you meet

- You need to be obsessive about learning new jargon so that you won't lose face

- Never admit to not knowing something

- It is more important to appear knowledgeable than to be competent

- It is important to quickly size up a situation and come to a decision

On the other hand, this behavior is the exact opposite of what it takes to make an end-user comfortable. Moreover, knowing that the end-user typically starts out with less technical knowledge, leads the analyst to assume they have lower status when, they are actually experts in their own discipline and often have more seniority. Plus, it leads to a tendency to quickly assume, he/she, as the technician, knows what the user wants. In reality, the user not only has useful knowledge about business processes and political considerations, they may also be able to contribute very useful expertise in the creation of an effective and usable system in general (ex: public relations personnel may have good ideas on presenting information effectively (Scalet, 2000/2001).

In my experience, senior IT majors in courses that emphasize management of technology (Global IT, Strategic IT) often get very angry when it is suggested that IT decisions derive from business decisions. It is their belief that IT directs the organization because it makes recommendations to end-users. Their viewpoint overstates the power of IT and will lead to problems when interacting with end-users. In one course, students are given an assignment to study an industry, its history, structure, degree of globalization and use of information technology. At that time, students are reminded that they work for a firm 
that is trying to survive in a given environment, that an IT position is not just an IT position with no connection to the firm's industry. Unfortunately for many students this fact comes as a revelation.

Even the way IT students view the business core courses they take can be improved. More than one nonIT professor has told me they dislike having IT majors in their courses and that it is especially bad when a class has a large proportion of IT majors. The professors complain that the IT majors are more likely to not attend class as regularly, not participate and feel the course is a waste. As one might expect, these students don't do very well and evaluate the instructor poorly. From my experience IT majors see business core courses as being:

- Just something you have to take to get the IT degree

- Courses that prevent you from taking more IT

- Important only so that you can communicate with end-users

- Important because you may want to start your own firm

Students who view business coursework in this way will be taken by surprise at the extent of the communication gap when they enter the workforce. Rather than attributing the communication gap to the lack of a common vocabulary and working with users to overcome the gap, they may overly rely on their technical knowledge and give user involvement only lip service.

\section{IT-User Gap Solutions in the IT Major Curriculum}

Happily, there are ways to improve the acculturation of our majors. First of all, students can be encouraged in class to become experts in certain areas and then have them work together on projects that require the expertise of all. In addition to reducing the perception that an IT professional has to know everything, it would also reinforce the need to share information and work collaboratively. This perspective goes beyond just suggesting that group projects are needed to force students to learn how to handle small group interaction. The emphasis here is on encouraging students to feel comfortable with their own limited knowledge, more willing to ask for help and to realize that working with others is critical for success. Because this training will avoid the 'I am more Knowledgeable than You' syndrome, the IT professional will be more willing to take the time to understand the user's situation (perspective gap, appreciation gap) and to listen when the user gives warning (foresight gap).

Consistently reinforcing the need to know the industry of the firm you work for and how its processes relate to its competitiveness will address the ownership gap on the IT side. To reduce the relationship and communication gap, it is necessary to stress the need to create relationships with end-users even when not in a project with them and the importance of finding a mentor with experience in relationship building.

User involvement has been a long standing tenet of IT practice and 'soft' system development methodologies are the norm but yet end-users still feel there is a chasm between them and their technicians. The organizational learning approach to systems development pedagogy espoused by Salaway (1987) might be a possible solution for reducing the perspective and appreciation gaps. The organizational learning approach is based on the premise that user/IT interactions should be geared towards the detection and correction of errors. Table 1 contrasts the focus of traditional analysts and analysts using an organizational learning approach: 
Whereas the traditional approach may work well in many situations, today's IT development projects tend to require the more collaborative approach espoused by organizational learning (for an excellent example of how the traditional approach functions see Lin and Confield, 2000). An analyst using the organizational learning approach would "seek out users with conflicting views and attempt to understand

\begin{tabular}{|l|l|l|}
\hline Governing Principles & $\begin{array}{l}\text { Traditional Approach } \\
\text { (Self-Centered) }\end{array}$ & $\begin{array}{l}\text { Organization Learning Approach } \\
\text { (We-Centered) }\end{array}$ \\
\hline Thought Process & I am rational & We are rational \\
\hline Control Orientation & I control tasks & I empower myself and others \\
\hline Effort Orientation & I win or lose & We win or lose \\
\hline Goal Orientation & Finish task w/ info. at hand & Act on valid information \\
\hline Causal Thinking & They cause problems for me & Active dialogue causes increased understanding \\
\hline Strategic Orientation & I understand what I need to do & I understand what we need to do \\
\hline Mode of Influence & Advocate position w/o testing & Advocate but invite inquiry \\
\hline
\end{tabular}

Table 1: Traditional vs. an Organizational Learning Approach to Analysis

the differences, and explicitly identify and tackle areas where problem resolution could be time consuming and significantly impact the project schedule or design." Students in systems analysis and design courses should be taught the organizational learning approach and given practice in its use until it becomes natural for them.

Cranfield University, through the creation of a new short seminar, has addressed the cultural and communication gaps directly (see Figure 3 below for a selection of course objectives). The seminar is entitled Organisational Politics and IT Management (Patching \& Chatham, 1998). Students, in a series of case scenarios, are encouraged to use their normal reasoning processes that result in huge mistakes. By forcing the students to see how their behavior is ineffective, it opens the door for a discussion of culture,

...We believed that, in order both to fight against the stereotype, and genuinely to be able to work effectively in the political arena, IT managers would need:

- $\quad$ The willingness and openness to acknowledge[the IT] stereotype and its impact on them as individuals

- A sense of humor to recognise their own shortcomings, especially where these reinforce the stereotype

- $\quad$ The ability to be comfortable in situations of ambiguity and uncertainty

- A preparedness to accept levels of responsibility for business success well outside their areas of direct accountability

- Skills in all forms of communication, beyond the communication of dry facts

- A team-oriented approach to problem resolution

- $\quad$ The subtle arts of leadership -- in all directions

- $\quad$ A full range of conflict-handling styles to deal with different situations in appropriate ways

- $\quad$ A sensitivity to the uniqueness of individuals and their different strengths, particularly when brought together in collaborative activities

- $\quad$ A culture of sincere customer focus within their IT functions

- $\quad$ A set of mutually compatible visions -- for themselves as individuals; for their families and friends; for their IT functions; and for their organisations

Figure 3: Organizational Politics Seminar Objectives values and influence be-

haviors. The course

"builds from an essentially collaborative style, in which different perspectives can be harmonised in 'win-win' solutions." The curriculum makes students aware that rational persuasion ('you should do it because it makes sense') as an influence strategy may not be enough (Enns, et al., 2000).

One case used in the seminar represents unsuccessful problem solving from one of the instruc- 
tor's own experiences ${ }^{1}$. The students read the case but don't know, at first, that the instructor is the protagonist. In the case, she (instructor) does all the right things from an IT management standpoint (sorts out their architecture, implements standards and procedures, etc). The outcome, however, was not successful because political and relationship management issues were mishandled. The students read the case and severely criticize the protagonist At that point, she tells them the case is about her. At first they are shocked, but then they begin to admit that they are in the same situation and guilty of the same lack of insight into political issues. Now, the students have broken through the acculturation of never saying you are wrong.

In the second case, an organization makes some naïve decisions when choosing a technical solution for a new information system and then creates increasingly larger cover-ups and repeatedly arguing their rationale in increasingly technical terms to avoid losing face instead of protecting the interests of the organization. Chatham's first step is to describe the organization's needs and ask the students to pick a technical solution. Students typically make the same naïve decision that the IT department in the case made because the situation is ambiguous and choice must be made on subjective criteria. She then unfolds the rest of the story, about how the project starts to fall apart and asks what would you do now that it is clear the chosen solution is a mistake? The organization is running fine without the new system but stopping the project will result in negative consequences. The case focuses on decision making in ambiguous situations and the discussion reinforces that the IT department is there to support the organization first and the importance of knowing the values with which you have been acculturated (saving face over competence, use of technical jargon and rational persuasion to influence others) and making decisions that in a way that is cognizant of the value issues involved.

After explaining the situation, she has her students make a decision. They make the same wrong decision as she did because they are using her frame of reference. She then explains why the decision was completely wrong given the social situation (appreciation gap). By showing them that the users sometimes are better able to predict what will happen (foresight gap), the students will be less likely to perceive end-user protests as just resistance to change. According to her, it takes two more failed decisions for them to see that there is a whole side to life in organizations that they are missing. From that point she can teach them new ways of looking at the world and dealing with the people in it. In essence, students become sensitized to the business culture as distinct from IT culture (cultural gap) and begin to see the world through the end-user's eyes (perspective gap). (Note: For more information on this teaching technique, contact Robina Chatham at R.Chatham@cranfield.ac.uk. Additional information on this issue can be found in Corporate Politics for IT Managers: How to Get Streetwise. Patching, Keith and Chatham, Robina. Boston, Butterworth-Heinemann, 2000).

Management of information systems courses for IT majors could address the IT/User gap in another form: impression management. The topic would cover ways in which an IT department loses credibility (credibility gap), feels misunderstood (perspective gap) or becomes unrecognized (appreciation gap) for its activities. Techniques for monitoring and improving the IT department's relationship with the rest of the organization should be discussed here.

To summarize, not only will all the changes suggested herein improve our majors chances of developing better systems (reduce the credibility gap), they will also make it more likely that the graduates will move up through increasingly responsible positions and be better able to handle cross-functional projects. There are, however, also things that can be done to reduce the IT/User gap from the business side.

\footnotetext{
${ }^{1}$ R. Chatham, personal communication at UKAIS (Association for Information Systems, United Kingdome region, Cardiff, Wales, April 27, 2000.
} 


\section{Implications for IT Curricula - Hybrid Majors}

Some universities are responding to the need for IT/User liaisons by creating specialist programs in the MBA curriculum (O'Connor \& Smallman, 1995). A model for this type of program that was suggested by O'Connor and Smallman uses a structure based on week long workshops that focus on an integration of technical awareness with 'soft' skills followed by an extended practicum.

There is also a role for a Hybrid Major in the undergraduate IT curriculum. Using a highly informal polling procedure at IT conferences for the past few years, it has been my habit to ask professors about how they handle the large number of students who want to be IT majors because they are lured by the promise of high salaries. Everyone admits that some of the people will never make good programmers; they just do not have the talent for it. Everyone also agrees that there is a role for people who have a strong interest in systems but who are not necessarily technically oriented. When asked about whether their department has a curriculum that can support the work of these types of people, they invariably say "no" and their eyes glaze over as if they have lost interest in the subject. This is unfortunate because the students feel rejected when, in actuality, they could be doing highly valuable work which actually would improve the end-user's view of the IT function. These same students who aren't technical enough to be third generation programmers can be trained to be IT-User intermediaries.

There are two ways to handle this in the curriculum. One way is to create an IT Liaison major. This major would be designed to give the students a full business core plus enough technical background to be able to talk to IT people. It would replace the heavy programming component with project, conflict and change management coursework.

"While an understanding of information technology and systems design is certainly useful, even necessary, an understanding of the business environment is more important than nitty gritty technical training for relationship managers (Whiting 1987)."

In addition to learning how to bridge the gap between IT and business units, these students would also learn how to create their own job descriptions $(60 \%$ to $65 \%$ of firms do not have defined duties for their liaisons), build relationships with IT/Users, document their effectiveness and deal with the pitfalls of being in an intermediary position between groups that may have long-standing conflict relationships. "But perhaps more important to a relationship manager than education or experience in business or technology is possessing 'soft skills," including the ability to establish relationships, manage conflicts, analyze information, communicate, listen, negotiate (Whiting, 1987)."

On the other hand, most IT/User liaisons come from the business side and have a higher success rate -$87 \%$ of business oriented liaisons are successful versus $35 \%$ of IT oriented liaisons (Foote, 1996). One explanation for this finding is that individuals with business experience, strong organizational savvy and a good general understanding of technology do better than technologists who are somewhat more socially adept than their peers. At the same time, students in the IT Liaison curriculum should be encouraged to minor in one of the business unit disciplines so as to highlight their hybrid emphasis.

\section{Implications for IT Curricula - Hybrid Minors}

A second or additional approach to creating hybrid personnel would be to create an End-User Support minor that could be taken by non-IT business majors who have an interest in working with IT while remaining in their own discipline.

The minor would include technical training geared towards end-user development in generic packaged software (ex: Visual Basic, Microsoft Access), web development tools (ex: Dreamweaver) and businessoriented software (ex: Enterprise Resource Planning, Customer Relations Management Systems). Since 
hybrid minors are likely to be doing business analysis and reporting, give them coursework in database mining and online analytical processing. In their role as advisors to end-users they will need information resource management courses such as IT strategy or supply chain management.

Majors in business departments such as accounting, finance, marketing, human resources in management and production would be more marketable if they had some exposure to the systems used by their respective business units. An End-User Support minor could also include a course for each business discipline that covers the systems built for that unit. For example, accounting majors who enjoy working with computers would enroll in this minor so as to learn a bit about the most common accounting software packages and how to help accounting get the most from its IT. Even general business administration majors would benefit from an End-User Support minor because it would widen their opportunities beyond General Manager positions. It might even be of interest to non-business majors in disciplines where IT has become critical might be interested in the minor. Table 2 summarizes the differences between the Hybrid major and minor.

\section{Discussion}

Many readers in IT will say, 'why do we need to change my curriculum or build new programs when we have too many majors now and they all can find jobs?' According to Whiting (1987), intermediaries are a response to the poor performance of IT in the 80 's. Our job is to educate professionals to be effective in organizations. More and more students are being recruited with only technical and associate degrees. By changing our curriculum, we can ensure that our graduates have something especially useful to other organizations: technical skills plus the ability to think outside the technical box.

In the past, IT departments were marginalized for many of the same reasons as those that cause the IT/User gap. The difference is that the gap is between business unit faculty and IT faculty (and our majors?). Now business departments have discovered IT's importance and have seen enrollments drop as students rush to enroll in IT. As they begin incorporating IT issues into their courses, the IT department may then be marginalized again. A hybrid minor would demonstrate that the IT department is best at educating people to manage the information resource even for students in other majors. If a student wants to become more marketable, he/she does not have to jettison one major and take on another; just

\begin{tabular}{|c|c|}
\hline Hybrid Major & Hybrid Minor \\
\hline \begin{tabular}{ll}
\multicolumn{2}{l}{ Technical Component } \\
- & Introduction to IT \\
- & End-User Development \\
- & Systems Analysis \\
- & Database \\
- & Networking \\
- & IT Electives
\end{tabular} & $\begin{array}{l}\text { Technical Component } \\
\text { - Introduction to IT } \\
\text { - } \quad \text { (customized to their major) } \\
\text { - } \text { End-User Development } \\
\text { - Data Mining and Analysis } \\
\text { - Development for the Web } \\
\text { - Information Resource Manage- } \\
\text { ment }\end{array}$ \\
\hline $\begin{array}{ll}\text { Relationship Component } \\
\text { - } & \text { Project Management } \\
\text { - } & \text { Change Management } \\
\text { - } & \text { Conflict and Resolution }\end{array}$ & \\
\hline
\end{tabular}
add a minor. Graduating students with low grades in IT because they are more interested in working with technology than creating it does a disservice to them and prevents them from finding positions in organizations where they can be very useful. A final advantage to the IT curriculum is that programming courses can become more rigorous because the students that remain in them have more of an interest and talent for programming.

To conclude, the hybrid major/minor would allow us to keep high enrollments, help all 


\section{IT Education's Failure to Deliver}

our majors reach their highest potential, increase the rigor of our technical course, improve our relationship with other faculty and boost our status in the business school.

\section{References}

Avital, M. \& Vandenbosch, B. (2000).The Relationship Between Psychological Ownership and IT-Driven Value. Proceedings of the International Conference of Information Systems, Sydney, Australia, 652-659.

Beccue, B. (1991). What Should Universities Be Teaching Future End-User Liaisons about Database? Journal of Information Systems Education Online, 3, 1-4 found at http://www.gise.org/JISE.

Champy, J. (1997). IT and Line Managers Need to Close the Gap. Computerworld, Jan. 27, 76.

Couger, J. D, et al. (1995). IT '95: Guideline for Undergraduate IT Curriculum. MIS Quarterly, September, 341-359.

Davenport, T. (1999). From Data to Knowledge. CIO Magazine Online, published April 1. Retrieved from the World Wide Web, http://www.cio.com.

Enns, H.G., Huff, S.L. \& Higgins, C. (2000). CIO Lateral Influence Behaviors: Gaining Peers' Commitment to Strategic Information Systems. Proceedings of the International Conference on Information Systems, Sydney, Australia, 457-460.

Essex P., Magal, S. \& Masteller, D. (1998). Determinants of Information Center Success. Journal of Management Information Systems, 15, 95-117.

Feeny, D. \& Willcocks, L. (1998). Core IT Capabilities for Exploiting Information Technology. Sloan Management Review, Spring, 9-21.

Fisher, J. (1999). Improving the Usability of Information Systems: The Role of the Technical Communicator. European Journal of Information Systems 8, 294-303.

Foote, D. (1996). The New Breed. CIO Magazine Online, published Nov. 1. Retrieved from the World Wide Web, http://www.cio.com.

Guimaraes, T., Gupta, Y. P. \& Rainer, R. K. (1999). Empirically Testing the Relationship Between End-User computing Problems and Information Center Success Factors. Decision Sciences, 10, 393-413.

Hale, D.P., Sharpe, S. \& Hale, J.E. (1999). Business-Information Systems Professional Differences: Bridging the Business Rule. Information Resources Management Journal, Apr-Jun, 16-25.

Hayes, F. (1997). Giving IT the Business. Computerworld, $31,8$.

Hayes, F. (1998). IT and the Big Picture. Computerworld, Feb. 23, 8-11.

How to Bridge the Gap? (1999a). Computer Weekly, Dec. 2, 88-89.

Kettinger, W. \& Lee, C. (1995). Exploring a 'Gap' Model of Information Service Quality. Information Resource Management Journal, Summer, 5-16.

LaPlante, A. (1997). Charting New Waters. Computerworld, (31:35), Sept. 1, 79-80.

Lin, A. \& Conford, T. (2000). Framing Implementation Management. Proceedings of the International Conference on Information Systems, Sydney, Australia, 2000, 197-205.

Mann, J. (1996). The Role of Project Escalation in Explaining Runaway Information Systems Development Projects: A Field Study. Unpublished Dissertation, Georgia State University, 1996.

Margolis, J. \& Miller, F. (n.d.) Geek Mythology. In the Women in Computer Sciences: Closing the Gender Gap in Higher Education website. Working Paper of the Carnegie Mellon Project on Gender and Computer Science (http://www2.cs.cmu.edu/ gendergap/geekmyth.html).

Martinsons, M. G. \& Chong, P.K.C. (1999). The influence of human factors and specialist involvement on information systems success. Human Relations, 52, 123-152.

McCann, J.M. (1995). Why Category Management Fails: Look to the MIS/Marketing Gap, Brandweek, 36, 18.

McGinnes, S. (n.d.) Communication and Collaboration: Skills for a New IT Professional, Computers in Teaching Initiative website from the Royal Holloway School of Management, http://www.ulst.ac.uk/citcomp/mcgin.html 
Melymuka, K. (1998). IT Managers Face Understanding Gap. Computerworld, 32, 54.

Miller, T.W. (1998). Wanted for Hire in 2010: Business Analysts. Marketing News, Dec. 7, 13-15.

Mottl, J.N. (1999). Respect, Training Top IT Wish List. Internetweek, Feb 1, 22-24.

New Group Will Bridge the Gap to Business. (1999). Computer Weekly, Oct. 7, 79-80.

O'Connor, G. \& Smallman, C. (1995). The Hybrid Manager: A Review. Management Decision, 33, 19-28.

Ouellette, T. (1999). Living with the Pain, Computerworld, Apr. 19, 50-53.

Patching, K. \& Chatham, R. (1998). Getting a Life at Work: Developing People Beyond Role Boundaries. Journal of Management Development, 17, 316-337.

Pender, L. (2000/2001). How to Communicate Value. CIO Magazine Online, published Dec. 15/Jan. 1. Retrieved from the World Wide Web, http://www.cio.com.

Rose, I. (1995). Retooling the Information Profession. Journal of Information Management, 46, 7-13.

Scalet, S.D. (2000/2001). The View from the Top. CIO Magazine Online, published Dec. 15/Jan. 1. Retrieved from the World Wide Web, http://www.cio.com

Seligman, L. (2000). Adoption as Sensemaking: Toward an Adopter-Centered Process Model of IT Adoption. Proceedings of the International Conference on Information Systems, 361-370.

Shah, H.U., Dingley, S. \& Golder, P. (1994). Bridging the Culture Gap between Users and Developers. Journal of Systems Management, 45, 18-21.

Shore, B. (1998). Managing End-User Challenges. Information Systems Management, 15, 79-83.

Standish Group. (1995). Most Programming Projects Are Late. West Yarmouth, MA.

The New Breed: Hybrid Finance/IT Managers. (1998). Management Accounting, 80, 46-50.

Trauth, E.M., Farwell, D. \& Lee, D. (1993). The IT Expectation Gap: Industry Expectations versus Academic Preparation. MIS Quarterly, 17, 293+.

Wallace, B. (1998). Frustrated Networking Pros Say Efforts Not Appreciated. Computerworld, Mar. 2, 12-14.

Whiting, R. (1998). Dangerous Liaisons. Software Magazine, April, 20-26.

Wynekoop, J.L. \& Walz, D.B. (1998). Revisiting the Perennial Question: Are IT People Different? Database for Advances in Information Systems, 29, 62-72.

\section{Biography}

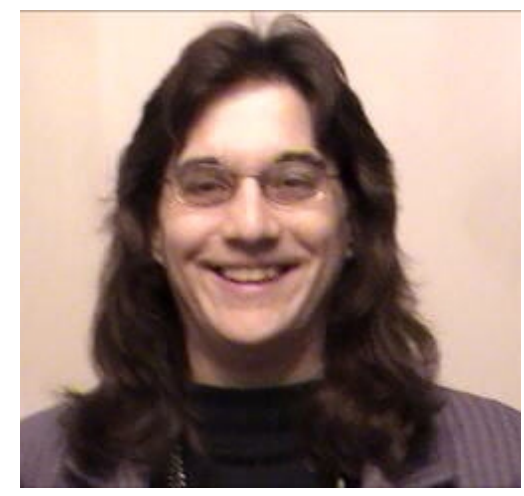

Joan Ellen Cheney Mann is an assistant professor at Old Dominion University. She holds a Ph.D. in Management Information Systems from Georgia State University. Her research generally focuses on Runaway IS projects, Global IT issues and other management of information topics. Professor Mann's research has been published in MIS Quarterly, European Journal of Operations Research, the IS Audit \& Control Journal and many national conferences including the Association for Information Systems, Academy of Management, Decision Science Institute. 